\title{
Evaluating Country-of-Manufacture Effects on Competitiveness
}

\author{
Tien-You Wang
}

\begin{abstract}
In modern market, consumer choice behavior attracts attention from researchers and manufacturers for its importance and unpredictability. Many factors influence consumer choice behavior, country of manufacture (COM), price, quality, design, and awareness are the most commonly mentioned in literature. This study aims at investigating the impact of COM effect on consumer choice behavior, and the most important factor in consumers' mind. Brand choice models are employed to evaluate consumer choice probabilities of seven countries of manufacture. The results show that quality is the most important product attribute, COM, design, price go next, followed by awareness. The choice probabilities are also estimated to show the competitiveness of these COMs in Taiwan market. This may provide manufacturers in these COMs relative information, and help promote their competitiveness.
\end{abstract}

Index Terms-Brand choice models, country of manufacture.

\section{INTRODUCTION}

In modern market, international trade has been thriving owing to globalization of economic processes, which makes an international product be no longer manufactured or designed by its brand-origin (BO) country. Triumphinternational, for example, was founded in Germany in 1886, and its multinational manufacturing and marketing organization operates in more than 120 countries around the world. Due to the complexity of source information, consumers are confused about their perception of the quality of an international product. In this case, country-of-origin (COO) image is critical when consumers decide whether to buy the product or not.

Dichter [1] was the first to argue that a product's COO may influence the acceptance of products, and the first empirical test of this notion was conducted by Schooler [2]. Since then, researches on $\mathrm{COO}$ had flourished from 70's to 90 's. In literature review by Verlegh and Steenkamp [3], most researches identified that $\mathrm{COO}$ does have an effect on consumers' purchase decision, it acts as the 'signal' for product quality [4]-[7]. Chao [8] distinguished hybrid and non-hybrid products, but argued that separating $\mathrm{COO}$ into COD (country of design) and country of manufacture (COM) may result in a decrease of the meaning that consumers attach to these constructs, so he suggested that it is worthwhile to explore how $\mathrm{COO}$ effect sizes are affected by multinational production. However, successive researchers tend to separate $\mathrm{COO}$ into $\mathrm{BO}, \mathrm{COM}$, and $\mathrm{COD}$, and compare

Manuscript received November 10, 2011; revised December 21, 2011.

T. - Y. Wang is with the Tainan University of Technology, Tainan, 71002 Taiwan (e-mail: prisca@seed.net.tw). the effects between them. Insch and McBride [9] concluded COD, COA (country of assembly) and COP (country-of-parts) do have different effects on product evaluations with the COP exhibiting the strongest influence. In their definition, COD is the country where the product was conceived and engineered. $\mathrm{COA}$ is the country where the majority of the product's final assembly occurred, and COP represents the country where the majority of the materials used in the product came from and/or the component parts were made.

Others extend this research and found that consumers are more sensitive to COD for symbolic meanings products than for private goods for which COM is important [10]. Furthermore, COM images exert an impact on brand quality, not brand image [9], [11]. From this point of view, COM is more important than $\mathrm{BO}$ and $\mathrm{COD}$ for private goods such as lady's underwear products, so this study focuses on COM effects to consumers' choice among competing lady's underwear products.

Lady's underwear products are highly associated with consumer preference, manufacturers need to know what influence consumers' choice among such products, and to what extent they will buy. Stochastic economic models are used for analyzing consumer choice behavior because of its uncertainty; such models are called brand choice models. The following section describes different branches of brand choice models and research methods, Section 3 illustrates implementation results, and Section 4 concludes the research.

\section{Evaluating CONSUmer ChOICE}

Consumer choice behavior always obtains manufacturers' attention for its unpredictability, evaluating consumer choice behavior thus becomes challenging and critical; brand choice models has been developed for this sake for decades. Manrai [12] had reviewed the development of brand choice models and illustrated their definition, branches and evolution, his work is abbreviated in next section.

\section{A. Review of Brand Choice Models}

A brand choice model represents the underlying process by which an individual consumer integrates information to select a brand from a set of competing brands. With varying assumptions and purposes, brand choice models differ in underlying logic structure that drives them. There are three categories of these models, namely, (1) multi-attribute choice models, (2) preference and choice mapping models, and (3) conjoint analysis. Among these three categories, the multi-attribute models play an important role in marketing applications. They have been used for determination of 
market structure, demand forecasting, product positioning, buyer segmentation, and prediction of consumer choice. These models are driven by two fundamental principles, namely, (1) the principle of utility maximization (brand-based processing), and (2) the psychological principle of attribute-based sequential elimination (attribute-based processing). The difference lies in the assumptions about the way consumer processes information.

The principle of utility maximization postulates that a consumer uses all relevant information and selects the brand that maximizes his/her utility. The basic choice process assumes that all of the attributes are considered in a simultaneous compensatory structure, thus assigning a utility value to each brand. Luce's model [13] is the earliest brand-based processing model; McFadden [14] extended and revised his model as the classical independent Multinominal Logit (MNL) model. Following brand-based processing models include Nested Multinominal Logit (NMNL) model [15], Multinomial Probit (MNP) model [16], Generalized Logit Model (GLM) [17], Multiplicative Competitive Interaction (MCI) model [18] etc.

The principle of attribute-based processing suggests that a consumer makes a selection through a simplified heuristic and may not use all the relevant information available at the time of choice. The choice is made by comparing brands on attribute-by-attribute basis. The assumption is that there is a random or hierarchical sequence in which the attributes are considered. Elimination-By-Aspects (EBA) Model [19] is a prime example of these models. Other models in this category include Elimination-by-Cutoffs (EBC) model [20], Elimination-by-Dimensions (EBD) model [21], and other EBA-like models.

\section{B. Methods}

The various brand choice models are based on different assumptions and purposes, so selecting an appropriate model among them has been more difficult than before. Matsatsinis and Samaras [22] presented a process of brand choice model selection, which refers to transformation of preference table, calculation of parameters such as range type, skewness and kurtosis, selection of an appropriate brand choice model, and finally estimation of choice probability. Other researches concern about complexity-induced choice inconsistency in choice set [23], or the factors that affect purchase decision. Most researchers conclude that price and quality have long-term effect on consumers' decision [24]-[26], so the importance of product attributes in consumers' mind is also investigated in this study.

Literature verified that country image affects consumers' perception of product quality, so this study chooses seven countries for implementation based on an official statistic report. Two of them are European countries, namely E1, E2, the rest are Asian countries, namely A1, A2, A3, A4, and A5. The choice set is simple, and an appropriate choice model is needed to evaluate consumers' choice behavior, so the process is employed for consumer choice analysis. The process involves the following steps:

1) Obtain preference tables from consumers.

2) Decide utility function $u_{i}\left(g_{i}\right)$ to transfer preference value $a_{i j}$ with coefficients $\beta_{j}$ into utility value $U_{i}$, in which $i$ stands for country and $j$ for product attribute.

$$
U_{i}=u_{i}\left(g_{i}\right)=\sum_{j} \beta_{j} a_{i j}
$$

where $i=1,2, \ldots, 7, j=1,2, \ldots, 5,0<U_{i}<1$.

3) Find maximum utility value $U_{\max }$ and minimum utility value $U_{\min }$, and calculate range $R$ and range type $\delta$.

$$
\begin{gathered}
R=U_{\max }-U_{\min } \\
\delta= \begin{cases}1 & \text { if } 0 \leq R \leq 0.1 \\
2 & \text { if } 0.1<R \leq 0.3 \\
3 & \text { if } 0.3<R \leq 0.6 \\
4 & \text { if } 0.6<R \leq 1\end{cases}
\end{gathered}
$$

4) Calculate $\varepsilon$ and $x_{i}$,

$$
\begin{gathered}
\varepsilon=\delta /(n-1) \\
x_{i}=U_{\min }+(2 i-1) \varepsilon / 2
\end{gathered}
$$

where $i=1,2,3, \ldots .6$.

5) Calculate $\mu$,

$$
\mu=\sum_{i=1}^{6} f_{i} x_{i} / \sum_{i=1}^{6} f_{i}
$$

6) Estimate $r^{\text {th }}$ moment $m_{r}$,

$$
m_{r}=\sum_{i=1}^{6} f_{i}\left(x_{i}-\mu\right)^{r} / \sum_{i=1}^{6} f_{i}
$$

7) Estimate skewness $\alpha_{3}$,

$$
\alpha_{3}=m_{3} / \sqrt{m_{2}^{3}}
$$

8) Estimate kurtosis $\alpha_{4}$,

$$
\alpha_{4}=m_{4} / m_{2}^{2}-3
$$

9) Search in the rule base listed in Appendix A with $\delta, \alpha_{3}$, and $\alpha_{4}$ to find a match. If a match is found, the selected model number is returned.

10) Estimate choice probability with the corresponding choice model in TABLE I.

This process extracts a consumer's intention of selecting a brand among competing brands, and quantifies the intention 
to choice probabilities.

TABLE I: BRAND CHOICE MODELS

\begin{tabular}{|c|c|c|}
\hline No. & Name & Model \\
\hline 1 & Luce & $P_{i j}(C)=U_{i j} / \sum_{k \in C} U_{i k}$ \\
\hline 2 & Lesourne & $P_{i j}(C)=U_{i j}^{2} / \sum_{k \in C} U_{i k}^{2}$ \\
\hline 3 & $\begin{array}{l}\text { Multinomial Logit } \\
\text { Model (McFadden-1) }\end{array}$ & $P_{i j}(C)=e^{U_{i j}} / \sum_{k \in C} e^{U_{i k}}$ \\
\hline 4 & McFadden-2 & $P_{i j}(C)=e^{2 U_{i j}} / \sum_{k \in C} e^{2 U_{i k}}$ \\
\hline 5 & Width of Utilities-1 & $P_{i j}(C)=U_{i j}^{U_{\max }-U_{\min }} / \sum_{k \in C} U_{i k}^{U_{\max }-U_{\min }}$ \\
\hline 6 & Width of Utilities-2 & $P_{i j}(C)=e^{\left(U_{\max }-U_{\min }\right) U_{i j}} / \sum_{k \in C} e^{\left(U_{\max }-U_{\min }\right) U_{i k}}$ \\
\hline 7 & Maximum of utilities & $\begin{array}{c}P_{i j}(C)= \begin{cases}1 / m & \text { if } U_{\max } \geq U_{j} \geq U_{\max }-\varepsilon_{i} \\
0 & \text { otherwise }\end{cases} \\
\text { where } \varepsilon_{i}=\left(U_{\max }-U_{\min }\right) /(n-1)\end{array}$ \\
\hline 8 & Equal probabilities & $P_{i j}(C)=1 / m$, where $U_{\max }-U_{\min } \leq 0.1$ \\
\hline
\end{tabular}

"Source: Matsatsinis and Samaras (2000)

\section{RESULTS AND DISCUSSION}

Questionnaire employed in this study consists of four parts: Part I contains demographic variables, Part II are questions of the most and the least favorite COMs, Part III investigates five product attributes, namely Quality, COM, Design, Price, and Awareness, and Part IV provides a preference table with dimension of $7 * 4$ (COM $*$ attribute).

\section{A. Data}

60 copies of original questionnaire are collected and analyzed with SPSS for pretest and adjustment. 300 copies of adjusted questionnaire are collected from female consumers by face-to-face interviewing in shopping malls, rail stations, night markets in Tainan and Kaohsiung. 263 out of 300 copies are effective, the statistic of demographic variables shows that students take $68.1 \%$ share in Profession, age group between 21 and 30 takes $66.9 \%$ share in Age, and store type of exclusive agency takes $43.3 \%$ share in Distribution variable.

\section{B. Country Image}

For realizing the image of selected COMs, Part II provides questions of the most favorite country and the least favorite one, and the reasons for each with Likert 5-point Scale. These reasons are separated into three dimensions, namely Ability of Production and R\&D, Product Quality and Reputation, and Level of National Economics. The Chronba Alpha values of the three dimensions are shown in TABLE II.

TABLE II: RELIABILITY ANALYSIS OF COUNTRY IMAGE DiMENSIONS

\begin{tabular}{ccc}
\hline \hline Dimensions & Most Favorite & Least Favorite \\
\hline Ability of Production and R\&D & 0.727 & 0.751 \\
Product Quality and Reputation & 0.846 & 0.824 \\
Level of National Economics & 0.783 & 0.865 \\
\hline \hline
\end{tabular}

The descriptive statistic results of the reasons of Most Favorite and Least Favorite COMs are as follow.

\section{1) The Most Favorite COM}

The most favorite COMs selected by consumers are E1, E2, and A2. The reasons of favorite are listed in TABLE III.

\begin{tabular}{c|ccc} 
TABLE III: REASONS AND EVALUATIONS OF THE MOST FAVORITE COMS \\
\hline \hline COM & E1 & E2 & A2 \\
\hline Reasons & & & \\
Ability of Production and R\&D & & \\
Excellent Technology & 4.34 & 4.27 & 3.95 \\
Product Innovation & 4.44 & 4.09 & 3.96 \\
& & & \\
Product Quality and Reputation & & & \\
Attractiveness of Product & 4.36 & 4.32 & 3.90 \\
Good Reputation of Product & 4.64 & 4.23 & 4.06 \\
Good Quality of Product & 3.73 & 3.68 & 3.36 \\
Level of National Economics & & & \\
High Living Quality & 4.43 & 3.96 & 3.76 \\
Image of Nobleness & 4.06 & 3.96 & 3.72 \\
\hline Average & 4.29 & 4.07 & 3.82 \\
\hline \hline
\end{tabular}

The results of $t$-test in TABLE IV show that the ranking of the above COMs is E1, E2, and A2, in this order.

TABLE IV: THE DIFFERENCE BETWEEN THE MOST FAVORITE COMS

\begin{tabular}{c|ccc}
\hline \hline Most favorite & E1 & E2 & A2 \\
\hline E1 & 0 & $0.22^{*}$ & $0.47^{* * *}$ \\
E2 & & 0 & $0.25^{* * *}$ \\
A2 & & & 0 \\
\hline \hline \multicolumn{2}{c}{${ }^{*} \mathrm{p}<0.05,{ }^{* *} \mathrm{p}<0.01,{ }^{* * *} \mathrm{p}<0.005$}
\end{tabular}

\section{2) The Least Favorite COM}

The least favorite COMs are A1, A3, and A4. The reasons of favorite are listed in TABLE $\mathrm{V}$.

TABLE V: REASONS AND EVALUATIONS OF THE LEAST FAVORITE COMS

\begin{tabular}{c|ccc}
\hline COM & E1 & E2 & A2 \\
\hline \hline Reasons & & & \\
Ability of Production and R\&D & 3.94 & 3.88 & 4.04 \\
Weak R\&D Ability & 3.84 & 3.96 & 3.75 \\
Out-of-date Technology & & & \\
& & & \\
Product Quality and Reputation & 4.54 & 4.00 & 3.92 \\
Bad Reputation of Product & 4.49 & 3.88 & 3.88 \\
Unsatisfied Quality of Product & & & \\
& & & \\
Level of National Economics & 3.98 & 3.88 & 3.67 \\
Low Living Quality & 3.92 & 3.75 & 3.88 \\
Unstable Economic Environment & 4.08 & 4.25 & 4.08 \\
Low Labor Cost & 4.07 & 3.94 & 3.87 \\
\hline Average & &
\end{tabular}

TABLE VI shows that the difference between each pair of $\mathrm{A} 1, \mathrm{~A} 3$, and A4 is not significant, so these three COMs have similar image in consumers' mind with each other.

TABLE VI: THE DifFERENCE BETWEen THE MOST FAVORITE COMS

\begin{tabular}{c|ccc}
\hline \hline Least Favorite & E1 & E2 & A2 \\
\hline E1 & 0 & 0.13 & 0.20 \\
E2 & & 0 & 0.07 \\
A2 & & & 0 \\
\hline \hline \multicolumn{5}{c}{${ }^{*} \mathrm{p}<0.05$}
\end{tabular}

\section{Importance of Product Attribute}

Part III is also analyzed with Likert 5-point Scale. In Part III, product attributes Quality, COM, Design, Price, and Awareness are investigated. Table 7 lists the averaged values of importance of the above attributes. 
TABLE VII: RANKING OF PRODUCT ATtRIBUTES

\begin{tabular}{c|c}
\hline \hline Attribute & Average \\
\hline Quality & 4.32 \\
COM & 4.07 \\
Design & 4.04 \\
Price & 3.97 \\
Awareness & 3.67 \\
\hline \hline
\end{tabular}

The ANOVA result in TABLE VIII shows that the difference between Quality and COM is significant, indicating Quality is unique and most important; the differences between pairs of COM and Design, COM and Price, Design and Price are not significant, meaning COM, Design, and Price are at similar influence level when consumers are selecting a product. Awareness is significantly different from COM, Design, and Price, so its importance follows them.

\begin{tabular}{|c|c|c|c|c|c|}
\hline Source & SS & DF & MS & $\mathrm{F}$ & P-value \\
\hline Q-C & 8.2814 & 1.0000 & 8.2814 & 17.3620 & 0.0000 \\
\hline C-D & 0.0932 & 1.0000 & 0.0932 & 0.1840 & 0.6681 \\
\hline C-P & 1.2852 & 1.0000 & 1.2852 & 2.4006 & 0.1219 \\
\hline D-P & 0.6863 & 1.0000 & 0.6863 & 1.3607 & 0.2439 \\
\hline C-A & 20.9601 & 1.0000 & 20.9601 & 38.8110 & 0.0000 \\
\hline D-A & 18.2586 & 1.0000 & 18.2586 & 35.8654 & 0.0000 \\
\hline P-A & 11.8650 & 1.0000 & 11.8650 & 22.0488 & 0.0000 \\
\hline
\end{tabular}

It is shown in TABLE VIII that Quality is at the first priority of consideration when consumers purchase lady's underwear products. COM, Design, and Price go next; none of the difference between each pair of them is significant, so they are granted the same important in consumers' mind. Followed is Awareness, indicating that for a multinational product, BO does not stand for quality, COM does; so COM is prior to Awareness.

These values are also tested by $t$-test, TABLE IX shows the difference values between the pairs and the results of $t$-test.

TABLE IX: T-TEST FOR DIFFERENCE BETWEEN PRODUCT ATTRIBUTES

\begin{tabular}{cccccc}
\hline \hline Attribute & Quality & COM & Design & Price & Awareness \\
\hline Quality & 0 & $0.25^{* * *}$ & & & \\
COM & & 0 & 0.03 & 0.10 & $0.40^{* * *}$ \\
Design & & & 0 & 0.07 & $0.37^{* * *}$ \\
Price & & & 0 & $0.30^{* * *}$ \\
Awareness & & & & 0 \\
\hline \hline
\end{tabular}

\section{Choice Probability Evaluation}

Part IV refers to a preference table which contains $a_{i j}, i=1$, $2, \ldots ., 7, j=1,2,3,4 . a_{i j}$ is transferred into utility value $U_{i}$ via a utility function. Table 10 is a real example of preference table. In this table, attributes Price, Quality, and Awareness are from questionnaire; Design is associated with brand strategy rather than COM, so it is not accommodated in preference table. On the other hand, product safety has been a hot issue recently, so Safety is accommodated to realize how consumers grant it.
TABLE X: A REAL EXAMPle OF PREFERENCE TABLE

\begin{tabular}{c|cccc}
\hline $\begin{array}{c}\text { Attribute } \\
\text { COM }\end{array}$ & Price & Quality & Awareness & Safety \\
\hline A1 & 1 & 1 & 2 & 1 \\
A2 & 3 & 5 & 4 & 4 \\
A3 & 1 & 3 & 2 & 2 \\
A4 & 1 & 3 & 2 & 2 \\
A5 & 1 & 3 & 3 & 3 \\
E1 & 5 & 5 & 5 & 5 \\
E2 & 5 & 5 & 5 & 5 \\
\hline \hline
\end{tabular}

TABLE XI shows the evaluation result of the above example, the overall result, and the result from MNL model alone for comparison.

\begin{tabular}{c|cccc} 
TABLE XI: & \multicolumn{4}{c}{ FINAL Results OF CHOICE PROBABILITY EVALUATION } \\
\hline $\begin{array}{c}\text { Result } \\
\text { COM }\end{array}$ & Utility & $\begin{array}{c}\text { Example } \\
\text { Probability }\end{array}$ & $\begin{array}{c}\text { Overall } \\
\text { Probability }\end{array}$ & $\begin{array}{c}\text { MNL } \\
\text { Probability }\end{array}$ \\
\hline A1 & 0.119 & 0.082 & 0.068 & 0.087 \\
A2 & 0.862 & 0.173 & 0.174 & 0.162 \\
A3 & 0.420 & 0.111 & 0.071 & 0.124 \\
A4 & 0.420 & 0.111 & 0.072 & 0.127 \\
A5 & 0.549 & 0.127 & 0.165 & 0.178 \\
E1 & 0.994 & 0.198 & 0.224 & 0.179 \\
E2 & 0.994 & 0.198 & 0.226 & 0.143 \\
\hline \hline
\end{tabular}

The parameters of this example are as follows: $U_{\max }$ is $0.994, U_{\min }$ is $0.119, R$ is $0.875, \delta$ is $4, \varepsilon$ is $0.146, \alpha_{3}$ is -0.123 , and $\alpha_{4}$ is -1.329 . Searching in rule base in Appendix A with $\delta, \alpha_{3}$ and $\alpha_{4}$ will get a returned model number, which corresponds to choice model in Table 1. The choice probability is estimated, and the evaluation process for one preference table is done. The averaged overall choice probability is the ultimate result from all preference tables. The overall result of MNL model alone is also presented for comparison with that of evaluation process. The results in Table 10 show that selection process outperforms MNL model alone by reflecting the share of each COMs more pertinently.

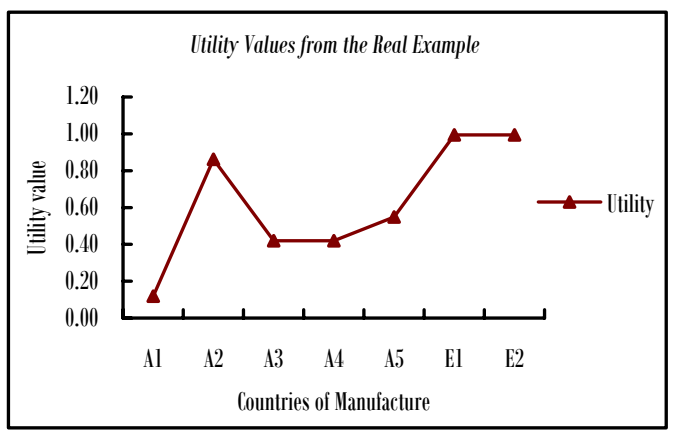

Fig. 1. Utility values of the real example.

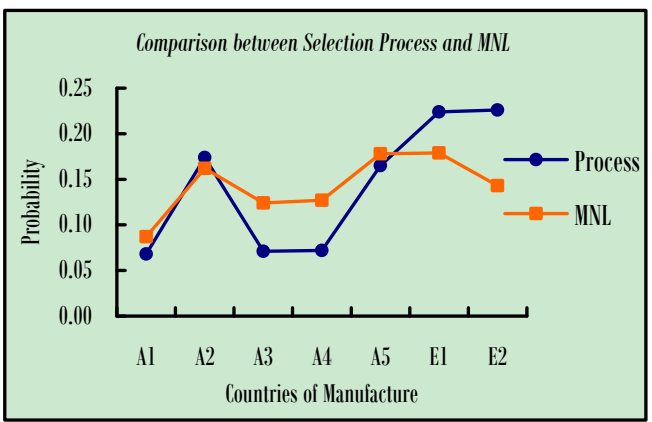

Fig. 2. Comparison between selection process and mnl model. 
Fig. 1 illustrates the utility pattern of the example, whereas Fig. 2 depicts the comparison between them. Apparently the selection process shows better ability of postulating similar pattern with utility pattern than MNL model alone does.

\section{CONCLUSION}

In modern market, when consumers are making their choice among competing multinational products, they are often confused about the complex source information. Researches validate COM image affects the perception of quality in consumers' mind, so this study explores how deep COM image effect may go. The final results reveal two aspects: (1) quality is at the first priority of consumers' purchase consideration, COM, design, price go next, followed by awareness. This means manufacturers are competitive if they focus on quality. (2) the overall choice probability indicates competitiveness share of each COM from a forward view. These countries of manufacture may predict their future share and make resource allocation in response. COM is the only variable employed for choice probability evaluation in this study; more variables such as price may be used to explore choice probability evaluation in future research.

\section{APPENDIX}

\section{A. Selection Rule for Brand Choice Models}

\begin{tabular}{|c|c|}
\hline Rule 1 & If $\delta=1$ then Model $=8$ \\
\hline Rule 2 & $\begin{array}{l}\text { if } \delta=2 \text { and }\left(\alpha_{3} \geqq-0.25 \text { and } \alpha_{3} \leqq 0.25\right) \text { and } \alpha_{4}<-0.5 \\
\text { then Model }=1\end{array}$ \\
\hline Rule 3 & $\begin{array}{l}\text { if } \delta=2 \text { and }\left(\alpha_{3} \geqq-0.25 \text { and } \alpha_{3} \leqq 0.25\right) \text { and }\left(\alpha_{4} \geqq-0.5\right. \\
\left.\text { and } \alpha_{4} \leqq 0.5\right) \text { then Model }=2\end{array}$ \\
\hline Rule 4 & $\begin{array}{l}\text { if } \delta=2 \text { and }\left(\alpha_{3} \geqq-0.25 \text { and } \alpha_{3} \leqq 0.25\right) \text { and } \alpha_{4}>0.5 \\
\text { then Model }=3\end{array}$ \\
\hline Rule 5 & if $\delta=2$ and $\alpha_{3}>0.25$ and $\alpha_{4}<-0.5$ then Model $=2$ \\
\hline Rule 6 & $\begin{array}{l}\text { if } \delta=2 \text { and } \alpha_{3}>0.25 \text { and }\left(\alpha_{4} \geqq-0.5 \text { and } \alpha_{4} \leqq 0.5\right) \\
\text { then Model }=3\end{array}$ \\
\hline Rule 7 & if $\delta=2$ and $\alpha_{3}>0.25$ and $\alpha_{4}>0.5$ then Model $=4$ \\
\hline Rule 8 & if $\delta=2$ and $\alpha_{3}<-0.25$ and $\alpha_{4}<-0.5$ then Model $=3$ \\
\hline Rule 9 & $\begin{array}{l}\text { if } \delta=2 \text { and } \alpha_{3}<-0.25 \text { and }\left(\alpha_{4} \geqq-0.5 \text { and } \alpha_{4} \leqq 0.5\right) \\
\text { then Model }=4\end{array}$ \\
\hline Rule 10 & if $\delta=2$ and $\alpha_{3}<-0.25$ and $\alpha_{4}>0.5$ then Model $=5$ \\
\hline Rule 11 & $\begin{array}{l}\text { if } \delta=3 \text { and }\left(\alpha_{3} \geqq-0.25 \text { and } \alpha_{3} \leqq 0.25\right) \text { and } \alpha_{4}<-0.5 \\
\text { then Model }=3\end{array}$ \\
\hline Rule 12 & $\begin{array}{l}\text { if } \delta=3 \text { and }\left(\alpha_{3} \geqq-0.25 \text { and } \alpha_{3} \leqq 0.25\right) \text { and }\left(\alpha_{4} \geqq-0.5\right. \\
\left.\text { and } \alpha_{4} \leqq 0.5\right) \text { then Model }=4\end{array}$ \\
\hline Rule 13 & $\begin{array}{l}\text { if } \delta=3 \text { and }\left(\alpha_{3} \geqq-0.25 \text { and } \alpha_{3} \leqq 0.25\right) \text { and } \alpha_{4}>0.5 \\
\text { then Model }=5\end{array}$ \\
\hline Rule 14 & if $\delta=3$ and $\alpha_{3}>0.25$ and $\alpha_{4}<-0.5$ then Model $=2$ \\
\hline Rule 15 & $\begin{array}{l}\text { if } \delta=3 \text { and } \alpha_{3}>0.25 \text { and }\left(\alpha_{4} \geqq-0.5 \text { and } \alpha_{4} \leqq 0.5\right) \\
\text { then Model }=3\end{array}$ \\
\hline Rule 16 & if $\delta=3$ and $\alpha_{3}>0.25$ and $\alpha_{4}>0.5$ then Model $=4$ \\
\hline Rule 17 & if $\delta=3$ and $\alpha_{3}<-0.25$ and $\alpha_{4}<-0.5$ then Model $=4$ \\
\hline
\end{tabular}

\begin{tabular}{|c|c|}
\hline & then Model $=5$ \\
\hline Rule 19 & if $\delta=3$ and $\alpha_{3}<-0.25$ and $\alpha_{4}>0.5$ then Model $=6$ \\
\hline Rule 20 & $\begin{array}{l}\text { if } \delta=4 \text { and }\left(\alpha_{3} \geqq-0.25 \text { and } \alpha_{3} \leqq 0.25\right) \text { and } \alpha_{4}<-0.5 \\
\text { then Model }=3\end{array}$ \\
\hline Rule 21 & $\begin{array}{l}\text { if } \delta=4 \text { and }\left(\alpha_{3} \geqq-0.25 \text { and } \alpha_{3} \leqq 0.25\right) \text { and }\left(\alpha_{4} \geqq-0.5\right. \\
\left.\text { and } \alpha_{4} \leqq 0.5\right) \text { then Model }=5\end{array}$ \\
\hline Rule 22 & $\begin{array}{l}\text { if } \delta=4 \text { and }\left(\alpha_{3} \geqq-0.25 \text { and } \alpha_{3} \leqq 0.25\right) \text { and } \alpha_{4}>0.5 \\
\text { then Model }=4\end{array}$ \\
\hline Rule 23 & if $\delta=4$ and $\alpha_{3}>0.25$ and $\alpha_{4}<-0.5$ then Model $=5$ \\
\hline Rule 24 & $\begin{array}{l}\text { if } \delta=4 \text { and } \alpha_{3}>0.25 \text { and }\left(\alpha_{4} \geqq-0.5 \text { and } \alpha_{4} \leqq 0.5\right) \\
\text { then Model }=6\end{array}$ \\
\hline Rule 25 & if $\delta=4$ and $\alpha_{3}>0.25$ and $\alpha_{4}>0.5$ then Model $=7$ \\
\hline Rule 26 & if $\delta=4$ and $\alpha_{3}<-0.25$ and $\alpha_{4}<-0.5$ then Model $=6$ \\
\hline Rule 27 & $\begin{array}{l}\text { if } \delta=4 \text { and } \alpha_{3}<-0.25 \text { and }\left(\alpha_{4} \geqq-0.5 \text { and } \alpha_{4} \leqq 0.5\right) \\
\text { then Model }=7\end{array}$ \\
\hline Rule 28 & if $\delta=4$ and $\alpha_{3}<-0.25$ and $\alpha_{4}>0.5$ then Model $=7$ \\
\hline
\end{tabular}

Source: Revised from Matsatsinis \& Samaras (2000)

\section{ACKNOWLEDGMENT}

Thanks to Ai-Jung Yeh and Li-Hsiu Liu for their effort of collecting and inputting data.

\section{REFERENCES}

[1] E. Dichter, "The world customer," Harvard Business Review, vol. 40, no. 4, pp. 113-122, 1962.

[2] R. D. Schooler, "Product bias in the Central American common market," Journal of Marketing Research, vol. 2, pp. 394-397, 1965.

[3] P. W. J. Verlegh and J. B. E. M. Steenkamp, "A review and meta-analysis of country-of-origin research," Journal of Economic Psychology, vol. 20, no. 5, pp. 521-546, 1999.

[4] R. Batra, V. Ramaswamy, D. L. Alden, J. -B. Steenkamp, and S. Ramachander, "Effects of brand local and nonlocal origin on consumer attitudes in developing countries," Journal of Consumer Psychology, vol. 9, no. 5, pp. 83-95, 2000.

[5] W. -K. Li, R. S. Wyer. "The role of country of origin in product evaluations: informational and standard-of-comparison effects," Journal of Consumer Psychology, vol. 3, no. 2, pp. 187-212, 1994.

[6] M. Thakor and L. Katsanis, "A model of brand and country effects on quality dimensions: issues and implications," Journal of International Consumer Marketing, vol. 9, no. 3, pp. 79-100, 1997.

[7] K. P. Zeugner-Roth, A. Diamantopoulos, and M. Á. Montesinos, "Home country image, country brand equity and consumers' product preferences: an empirical study," Management International Review, vol. 48, no. 5, pp. 577-602, 2008.

[8] P. Chao, "Partitioning country-of-origin effects: Consumer evaluations of a hybrid product," Journal of International Business Studies, vol. 24, pp. 291-306, 1993

[9] G. S. Insch and J. B. McBride, "The impact of country-of-origin cues on consumer perceptions of product quality: a binational test of the decomposed country-of-origin construct," Journal of Business Research, vol. 57, no. 3, pp. 256-265, 2004.

[10] L. Hamzaoui and D. Merunka, "The impact of country of design and country of manufacture on consumer perceptions of bi-national products' quality: an empirical model based on the concept of fit," Journal of Consumer Marketing, vol. 23, no. 3, pp. 145-155, 2006.

[11] L. H. Hamzaoui, D. Merunka, and B. Bartikowski, "Brand origin and country of manufacture influences on brand equity and the moderating role of brand typicality," Journal of Business Research, vol. 64, no. 9, pp. 973-978, 2011.

[12] A. K. Manrai, "Mathematical models of brand choice behavior," European Journal of Operational Research, vol. 82, no.1, pp. 1-17, 1995.

[13] R. D. Luce, Individual Choice Behavior: A Theoretical analysis, NY: Wiley, 1959.

[14] D. McFadden, "Quantal choice analysis: A survey," Annals of Economics and Social Measurement, vol. 5, pp. 363-390, 1976. 
[15] D. McFadden, "Modeling the choice of residential locations," in A. Karlquist et al. (eds.), Spatial Interaction Theory and Residential Location, North-Holland, Amsterdam, pp. 75-96, 1978.

[16] I. S. Currim, "Predictive testing of consumer choice models that are not subject to independence of irrelevant alternatives," Journal of Marketing Research, vol. 19, pp. 208-222, 1982.

[17] S. R. Dalal and R. W. Klein, "A flexible class of discrete choice models," Marketing Science, vol. 7, no. 3, pp.232-251, 1988.

[18] L. G. Cooper and M. Nakanishi, Marketing Share Analysis. Kluwer, Boston, MA, 1988

[19] A. Tversky, "Elimination by aspects: A theory of choice," Psychological Review, vol. 79, no. 4, pp. 281-299, 1972.

[20] A. K. Manrai and P. K. Sinha, "Elimination-by-cutoffs," Marketing Science, vol. 8, no.2, pp. 133-152, 1989.

[21] D. H. Gensch and S. Ghose, "Elimination by dimensions," Journal of Marketing Research, vol. 29, no. 4, pp. 417-429, 1992.

[22] N. F. Matsatsinis and A. P. Samaras, "Brand choice model selection based on consumers' multicriteria preferences and experts' knowledge," Computer and Operations Research, vol. 27, no. 7-8, pp. $689-707,2000$

[23] J. R. DeShazo, "Designing choice sets for stated preference methods: the effects of complexity on choice consistency," Journal of Environmental Economics and Management, vol. 44, pp. 123-143, 2002.

[24] K. Pauwels, D. M. Hanssens, and S. Siddarth, "The long-term effects of price promotions on category incidence, brand choice, and purchase quantity," Journal of Marketing Research, vol. 39, no. 4, pp. 421-439, 2002.
[25] S. Chib, P. B. Seetharaman, and A. Strijnev, "Model of brand choice with a no-purchase option calibrated to scanner-panel data," Journal of Marketing Research, vol. XLI, pp. 184-196, 2004.

[26] T. Erdem, M. P. Keane, and B. Sun (February 2005), A dynamic model of brand choice when price and advertising signal product quality. Available:

https://student-3k.tepper.cmu.edu/GSIADOC/WP/2006-E45.pdf

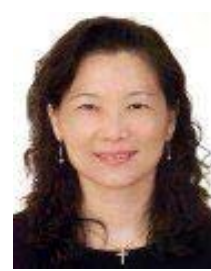

Tien-You Wang earned her Ph.D. degree at the end of 2006 from Department of Business Administration, National Chung Cheng University, Taiwan. Her major field is Operations Management, and her doctoral thesis focuses on integrated forecasting model with consumer choice analysis in its core. Her master degree was earned from Department of Computer Science \& Engineering, Lehigh University, U.S.A. She has been an Associate Professor in Department of Business Administration in Tainan University of Technology in Taiwan since the beginning of 2007, and her teaching courses include both Operations Management and Information Technology. In addition to the teaching job, she had been an Associate Engineer in Institute of Information Technology for two years, which is the leading research center in information technology domain in Taiwan. The main topic of Dr. Wang's research refers to integrated forecasting with evaluation of consumer choice. 